\title{
Os visitantes do Santuário de Panóias: um estudo patrimonial de um sítio arqueológico português
}

\author{
Visitors to Panóias Sanctuary: an equity study of an archaeological site Portuguese
}

\section{Fábio Vergara Cerqueira}

\section{Rute Teixeira}

Universidade Federal de Pelotas - UFPEL - Pelotas - Rio Grande do Sul - Brasil

Resumo: O trabalho de investigação aqui enunciado, só foi possível num espaço culturalmente enriquecido por um legado histórico de extremo valor, como o Santuário de Panóias, localizado em Vila Real - Portugal, que durante alguns anos recolheu informação sobre o perfil dos visitantes e o seu nível de satisfação com o Monumento. Este estudo teve como principais objetivos caracterizar sócio demograficamente os públicos que visitaram o Santuário entre 1996 e 1999 e entre 2006 e 2011, e ouvir as suas opiniões e propostas de melhoria.

Para concretização destes objetivos foram construídos três instrumentos de investigação: inquérito por questionário, inquérito por entrevista e grelha de observação direta. A investigação desenvolveu-se entre a análise quantitativa e qualitativa e o cruzamento de dados mostrou-se fundamental em todo este processo. Tendo em conta o objetivo da investigação, concluímos que os públicos que, maioritariamente visitaram o Santuário de Panóias,no período analisado, caraterizam se por ser um público maioritariamente feminino, detentor de habilitações académicas elevadas e profissões qualificadas, sendo, portanto, portadores de um forte capital cultural já intrínseco e enraizado.

Palavras-chave: Valorização cultural. Sítios patrimoniais. Santuário de Panóias.

Abstract: The research work here stated, was only possible in a culturally rich area for a historical legacy of extreme value, as Panóias Shrine, located in Vila Real - Portugal, which for some years has collected information on the profile of visitors and their level satisfaction with the Monument.

This study had the main objectives characterize socio demographically public who visited the shrine between 1996 and 1999 and between 2006 and 2011, and listen to their views and proposals for improvement.

To achieve these objectives were built three research instruments: questionnaire survey, interview survey and direct observation grid. The investigation developed between the quantitative and qualitative analysis and data crossing proved to be crucial in this process.

Having regard to the purpose of the investigation, we concluded that the public who mostly visited the Panóias Shrine, in the analyzed period, are characterized by being a mostly female audience, holder of high academic and skilled occupations, and therefore carriers a strong cultural capital has intrinsic and rooted.

Keywords: Cultural development. Heritage sites. Panóias Santuary. 


\section{A valorização do património: uma intenção contemporânea}

A literatura dos últimos anos permite-nos entender claramente que os autores contemporâneos se têm debruçado consideravelmente sobre os conceitos de Cultural e de Valorização Cultural, devido ao valor intemporal que estes mantêm na Sociedade atual, produto de um Mundo em constante mutação.

Daí a relevância que estas temáticas possuem na nossa Sociedade, na medida em que se torna fundamental consciencializar os indivíduos para a importância da conservação, restauro e valorização do Património Cultural.

Ao nível da temática da Cultura encontramos autores como RUíZ (2006,p.190) que entende a Valorização da Cultura e do Património Cultural como um "elo de sustentação, de identificação, de herança e de riqueza histórica, bem como um suporte de diferenciação, atratividade e singularidade de uma região".

De acordo com este teórico, interessa preservar o Património como forma de perpetuar a memória coletiva, como forma de dar a conhecer os valores culturais que transcendem a nossa Sociedade, como relíquias que trazem consigo o legado histórico e a identidade de uma Sociedade.

Ainda sob a perspetiva de RUíz (2006,p.195)revelamos que este define a filosofia da Cultura como "a disciplina que se propõe a explicar o fenómeno da Cultura, partindo de suas leis mais essenciais, investigando as causas da sua génese, as normas da sua transformação, as condições do seu crescimento e decadência dos seus conteúdos".

O teórico considera que a grande finalidade da Cultura é a orientação crítica para o desenvolvimento da vida intelectual, sendo os seus valores: verdade, beleza, justiça, santidade, realizados como produtos culturais concretos.

Assim sendo, a Cultura diz respeito a todas as "criações positivas do Homem, quer sejam de caráter material ou de índole espiritual, e a sua transmissão se processa simultaneamente das gerações mais velhas para as mais jovens, sendo muitas vezes geradora de conflitos e de resistência por parte dos indivíduos que constroem a nossa Sociedade" (RUíZ, 2006, p.166).

Neste sentido, conclui-se que a Cultura diz respeito a toda a criação diária que o Homem concretiza e que foi fruto das suas aprendizagens enquanto Ser Social.

Outro estudioso deste domínio, refere que a "Cultura é um processo de valorização do humanismo, isto é, mais de formação de caráter, do que de transmissão de saber" (CARVALHO,1999,p.70). Para este autor "a Cultura não se caracteriza pela sedimentação histórica dos seus produtos em permanência, mas pelo dinamismo ativo e agónico de novas intenções, valores e ideais" (CARVALHO,1999,p.72).

Neste sentido a Cultura é entendida "como um aspeto primordial da presença humana no Mundo, porque engloba as possibilidades que o Homem tem para emprestar provisoriamente às coisas, aos outros e a si mesmo" (CARVALHO,1999,p.76). Ou seja, "a Cultura é o produto do esforço humano" (RUÍZ,2006,p.165).

Ao aprofundarmos o conceito de Cultura, importante será agora dedicarmo-nos á questão da Valorização Cultural do Património.

Refletir sobre a importância da Valorização do Património Cultural permite-nos fazer uma abordagem em termos de atratividade, autenticidade e diferenciação de uma região, condição através da qual esta será revalorizada em questão de imagem e de identidade.Mais uma vez, RUíz (2006,p.165) dedica-se a esta temática referindo que o Património Cultural "comtempla tudo aquilo que caracteriza um Povo, desde os vestígios pré-históricos, cidades antigas, monumentos e todo o legado herdado pelas gerações anteriores em termos de tradições, lendas e gastronomia, que nos atribuem uma identidade cultural e nos permite reconhecer como algo que faz parte do nosso Ser".

Partilhando a mesma ideia, CASASSOLA (1990,p.31) argumenta que "Património Cultural de uma região é constituído por todas as manifestações 
tangíveis e intangíveis produzidas na Sociedade, constituindo-se como fatores de identificação e de diferenciação de um Povo".

Neste seguimento, a Carta de Veneza (1964), salienta que "o conceito de monumento histórico engloba, não só as criações arquitetónicas isoladamente, mas também os sítios, urbanos ou rurais, nos quais sejam patentes os testemunhos de uma civilização particular, de uma fase significativa da evolução ou do progresso, ou algum acontecimento histórico. Este conceito é aplicável, quer às grandes criações, quer às realizações mais modestas que tenham adquirido significado cultural com o passar do tempo".

A Convenção do Património Mundial (1972) vem consolidar estas afirmações quando afirma que são considerados como Património Cultural "os monumentos: obras arquitetónicas, de escultura ou de pinturas monumentais, elementos de estruturas de caráter arqueológico, inscrições, grutas e grupos de elementos com valor universal excecional do ponto de vista da história, da arte ou da ciência; os conjuntos: grupos de construções isolados ou reunidos que, em virtude da sua arquitetura, unidade ou integração na paisagem, têm valor universal; os sítios: obras do homem, ou obras conjugadas do homem e da natureza, e as zonas, incluindo os sítios arqueológicos, com um valor universal excecional do ponto de vista histórico, estético, etnológico ou antropológico excecional do ponto de vista da história, da arte ou da ciência".

Património Cultural é "fonte partilhada de memória, compreensão, identidade, coesão e criatividade" (Convenção de Faro, 2005). "É o conjunto das obras do Homem nas quais uma comunidade reconhece os seus valores específicos e com os quais se identifica. A identificação e a valorização destas obras como Património é, assim, um processo que implica a seleção de valores" (Carta de Carcóvia, 2000).

Desta forma, denota-se que a Valorização Cultural "deverá assegurar a sustentabilidade futura de uma região, construindo e consolidando uma imagem credível e consistente, respeitando o
Património Cultural enquanto bem não renovável" (BARATA,2002,p.150).

Indo ao encontro desta intenção, KLAMER (2000,p.14) considera que "a única forma de obtermos os benefícios do Património Cultural é pensá-lo dentro do contexto de sustentabilidade".

Neste domínio, destacaremos o ICOMOS, fundado em 1965, como sendo o principal consultor da UNESCO, em matéria de conservação e preservação do Património.A sua ação passa pelos seguintes objetivos:Congregar os especialistas em património e ser um fórum internacional para o diálogo e troca de experiências;Recolher, aprofundar e difundir informações sobre princípios, técnicas e políticas de conservação e restauro do património construído;Encorajar a adoção e implementação de convenções e recomendações internacionais respeitantes à proteção, conservação e valorização dos monumentos, conjuntos e sítios.

Ao abordarmos o Património Cultural como herança do passado, transmissor de grandes valores não poderemos deixar de referir novamente, a Carta de Veneza (1964), que define um conjunto de princípios orientadores relativos á conservação e restauro do Património, salientando que "cada país fica responsável pela aplicação desses princípios no âmbito específico do seu contexto cultural e das suas tradições".

Para reforçar a proteção, a conservação e a valorização do Património Mundial, a UNESCO em 1972 elaborou um novo documento: "Convenção do Património Mundial".

Este documento visa "a identificação, proteção, conservação, valorização e transmissão às gerações futuras do património cultural e natural de valor universal excecional" (Orientações Técnicas para Aplicação da Convenção do Património Mundial, 2010). Reforçando o que ficou estabelecido na Carta de Veneza (1964), a Convenção do Património Mundial (1972) refere também que "o Estado e seus parceiros devem certificar-se de que a utilização sustentável do Património Cultural não tem efeito negativo sobre o valor universal excecional, a integridade e/ou a autenticidade do bem. Além disso, 
qualquer utilização deve ser ecológica e culturalmente sustentável”.

Ao analisarmos as atitudes e os comportamentos da Sociedade atual, verificamos que os indivíduos exigem cada vez mais a proteção cultural do seu Património, bem como a transmissão destes valores às gerações vindouras, como forma de perpetuar um legado histórico que confere uma identidade social e cultural a cada cidadão.

Neste seguimento podemos citar a Carta de Carcóvia (2000) na medida em que esta refere que "o objetivo da conservação dos monumentos e dos edifícios com valor histórico é de manter a sua autenticidade e integridade.

Tal conservação requer um "projeto de restauro" que defina os métodos e objetivos a ter em conta". O "projeto de restauro" deve garantir uma relação correta com o conjunto envolvente, incluindo o ambiente, a decoração e a escultura e respeitando as técnicas tradicionais da construção e a sua necessária integração como uma parte substancial do património construído" (Carta de Carcóvia, 2000).

E como o conceito de Valorização Cultural evolui ao longo dos tempos, será importante introduzir o tema de Itinerários Culturais, desenvolvido pelo ICOMOS em 2008 na Carta dos Itinerários Culturais.

Analisar o conceito de Itinerários Culturais implica perceber que este "enriquece a mensagem espiritual do passado, e reforça a conceção contemporânea dos valores do património para a sociedade" (Carta dos Itinerários Culturais, 2008). Ou seja, "esta noção alargada do Património sugere novas abordagens de tratamento no interior de um contexto muito mais amplo, a fim de explicar e de salvaguardar as relações significativas diretamente associadas ao seu meio cultural e histórico, assim como ao seu ambiente natural ou criado pelo Homem" (Carta dos Itinerários Culturais,2008).

É neste sentido que o conceito de Itinerário Cultural é inovador, na medida em que traduz uma abordagem multidimensional de Património Cultural, representando um processo interativo e dinâmico das relações humanas interculturais, sobrevalorizando desta forma as contribuições dos diferentes Povos para o Património Cultural.

Centrar-nos-emos de seguida no caso Português. Segundo JORGE (2000,p. 6) "a defesa e a conservação dos bens culturais são hoje reconhecidas como uma incumbência fundamental do Estado Português, apoiando-se na sua ampla conjuntura politica, social, económica, cultural e ambiental" cumprindo desta forma, compromissos internacionais assumidos com a Organização das Nações Unidas.

Tal como os vários autores até agora referenciados, o Estado Português define como Património Cultural "todos os bens que, sendo testemunhos com valor de civilização ou de cultura portadores de interesse cultural relevante, devam ser objecto de especial proteção e valorização" (Lei do Património Cultural, 2001).

Concluímos desta forma que é tarefa fundamental do Estado Português e dever do Cidadão Nacional conservar e valorizar o Património Nacional, como forma de salvaguardar um espaço coletivo enriquecedor, colocado ao serviço do Homem,

Segundo a Lei do Património Cultural (2001) compete ao Estado Português: "incentivar e assegurar o acesso de todos à fruição cultural!". Pretende-se que todos os cidadãos nacionais tenham o direito a usufruir do Património Cultural Português, como forma de potenciar o desenvolvimento da sua personalidade através da realização cultural.

"Vivificar a identidade cultural comum da Nação Portuguesa e das comunidades regionais e locais a ela pertencentes e fortalecer a consciência da participação histórica do Povo português em realidades culturais de âmbito transnacional", é outro dever do Estado Português previsto na Lei do Património Cultural (2001).

"Promover o aumento do bem-estar social e económico e o desenvolvimento regional e local" é outro objetivo do Estado Português previsto na Lei do Património Nacional (2001). Neste sentido, o Estado ao investir na Cultura local, promovendo o turismo e apostando na projeção cultural do Património, estará 
a contribuir em grande escala para o crescimento económico da região e, por conseguinte para o aumento da qualidade de vida dos cidadãos.

Por último, a Lei do Patrimônio Nacional (2001) prevê que o Estado Português tem como dever "defender a qualidade ambiental e paisagística". Além de ser responsável pela preservação e valorização dos bens culturais, o Estado tem de desenvolver ações que promovam o desenvolvimento sustentável das regiões, preservando o meio ambiente e melhorando a qualidade do espaço envolvente.

É importante viver num País onde os bens culturais sejam entendidos como tesouros ou relíquias, portadores da história de cada Nação, que nos concedem uma identidade única, e que nos distinguem dos outros Povos, também eles portadores de uma vivência singular. Mas também, é fundamental que todos os cidadãos tenham a possibilidade de participar ativamente no usufruto do Património cultural, como forma de desenvolvimento pessoal e de integração social, conferindo-lhes um sentimento de pertença e de patriotismo, mas também de sabedoria e conhecimento, tao relevantes no incremento de uma consciência social ativa.

VINUESA (2003,p.5) vai ao encontro destas ideias quando refere que "recuperar o Património Cultural requer um esforço de imaginação e de realismo, tentando encontrar novos equilíbrios nas realidades económicas e socias, instrumentalizando políticas que tenham como objetivo reforçar o compromisso social de preservação do Património Cultural".

\section{Investigação empírica: 0 Santuário de Panóias - um palco de atuação}

A investigação que foi levada a cabo no âmbito da temática aqui desenvolvida, só foi possível ser concretizada num espaço culturalmente enriquecido por um legado histórico de extremo valor, como o Santuário de Panóias, em Vila Real - Portugal.

O Santuário de Panóias, durante muitos anos denominado por Fragas de Panóias, está classificado como Monumento Nacional desde 1910, é propriedade do Estado, e está afeto à Direção Regional de Cultura do Norte. É conhecido desde o séc. XVIII (ARGOTE, 1734) e foi objeto de estudos e investigação até aos nossos dias, por parte de investigadores nacionais e estrangeiros, sendo que com os trabalhos e a interpretação de GÉZA ALFOLDY (1997) foi possível de fato identificar este espaço como um espaço sagrado, um Santuário, da época romana, dedicado a Serápis, divindade oriental.

O Santuário de Panóias é constituído por um recinto onde se encontram três (entre outras) grandes fragas onde foram talhadas várias cavidades, de diversos tamanhos, bem como escadas de acesso. Numa das rochas foram também gravadas inscrições.

Existem hoje três inscrições em latim e uma em grego, e nelas estão as instruções dos rituais celebrados em Panóias, a identificação dos deuses e a do dedicante. Podem traduzir-se da seguinte maneira: "G.C. Calpurnius Rufinus consagrou dentro do templo (templo entendido como recinto sagrado), uma aedes, um santuário, dedicado aos Deuses Severos";"Aos Deuses e Deusas e também a todas as divindades dos Lapitaes, Gaius C. Calpurnius Rufinus, membro da ordem senatorial, consagrou com este recinto sagrado para sempre uma cavidade, na qual se queimam as vítimas segundo o rito."

"Ao altíssimo Serápis, com o Destino e os Mistérios, G. C. Calpurnius Rufinus, claríssimo." "Aos deuses, G. C. Calpurnius Rufinus, claríssimo, com este (templo) oferece também uma cavidade para se proceder à mistura."

Com base nos estudos sobre o monumento, podemos hoje dizer que tivemos no local um ritual de iniciação com uma ordem e um itinerário muito preciso - a matança das vítimas, o sacrifício do sangue, a incineração das vítimas, o consumo da carne, a revelação do nome da autoridade máxima dos infernos, e por fim a purificação. Hoje em qualquer das três rochas temos vestígios dos pequenos templos que eram parte integrante do recinto. Temos portanto em Panóias testemunhos de um rito de iniciação dos mistérios das divindades infernais. 
A construção deste recinto sagrado teria sido realizada neste local entre os finais do Séc. II e os inícios do Séc. III.

\section{A investigação empírica}

O grande intuito desta investigação foi caracterizar socio demograficamente os visitantes do Santuário de Panóias, e qual a sua opinião sobre o Monumento.

O estudo de caso foi a estratégia de investigação utilizada no desenvolvimento deste trabalho. Para YIN (1993,p.32) "um estudo de caso é uma investigação empírica que investiga um fenómeno contemporâneo dentro do seu contexto de vida real, especialmente quando os limites entre o fenómeno e o contexto não estão claramente definidos". Embora, o paradigma qualitativo esteja a ganhar terreno em relação ao quantitativo, um grande número de autores chama a atenção para as vantagens que se podem obter com "a combinação de métodos vindos dos dois paradigmas" (FRAGOSO, 2000,p.16).

Atendendo ao âmbito da presente investigação e aos seus objetivos, os instrumentos utilizados para a recolha de dados foram: inquérito por entrevista, inquérito por questionário e grelha de observação direta.

Esta observação foi construída com base num modelo analítico teórico-prático, na medida em que os dados recolhidos foram trabalhados posteriormente e, em conformidade com os que primariamente emergiram da interação com os atores sociais.

\section{- A recolha dos dados}

Para a realização deste estudo foram construídos instrumentos de investigação que se adaptassem aos objetivos da pesquisa: Inquérito por questionário (aplicado a todos os visitantes);Inquérito por entrevista (aplicado ao Responsável e Guia do Santuário);Grelha de observação direta (utilizada para observar no "terreno" aspetos de grande relevo).

"O questionário é tanto um ponto de chegada de uma reflexão como o ponto de partida para análises ulteriores" (ALBARELO,1997,p.85) e, segundo TUCKMAN (2000,p.100), é "utilizado pelos investigadores, para transformar em dados a informação recolhida mediante interrogação de pessoas (ou sujeitos) e não observando-as ou recolhendo amostras do seu comportamento".

A construção do inquérito por questionários, não foi da responsabilidade do investigador, mas sim da Direção Geral de Cultura do Norte, que elaborou dois modelos a serem aplicados em momentos diferentes: um entre 1996 e 1999 e o seguinte entre 2006 e 2011.

Relativamente ao processo de amostragem, do qual depende a validade que permite a posterior generalização de resultados, não deve ser deixada ao acaso, pois pretender-se uma amostra o mais representativa possível. Nesta Investigação o universo da amostra contou com 711 indivíduos.

A aplicação dos questionários ocorreu entre dois períodos distintos: 1996 a 1999 e 2006 a 2011.Desta forma, para evitar a distorção dos resultados, tivemos o cuidado de encorajar os visitantes a responder individualmente ao inquérito, após finalizarem a visita ao Santuário de Panóias.

Mediante a análise dos 711 inquéritos, que constituíram a amostra do estudo, foi possível categorizar diferentes dimensões relativas ao Santuário de Panóias (Quadro 1:Teixeira,2013,p.67), sendo estas o suporte da análise e da conclusão dos resultados finais da investigação.

\section{Quadro 01: Dimensões analisadas no Santuário de Panóias}

\begin{tabular}{|l|l|}
\hline Categorias & \\
\hline & Subcategorias \\
\hline & Receção ao visitante \\
\hline Acolhimento & $\begin{array}{l}\text { Profissionalismos e simpatia } \\
\text { dos funcionários }\end{array}$ \\
\hline Visita Guiada & \\
\hline
\end{tabular}




\begin{tabular}{|c|c|}
\hline $\begin{array}{l}\text { Acessos } \\
\text { Santuário }\end{array}$ & $\begin{array}{l}\text { Acessibilidades } \\
\text { Estacionamento }\end{array}$ \\
\hline Sinalética & \\
\hline $\begin{array}{l}\text { Apresentação } \\
\text { espaço }\end{array}$ & $\begin{array}{l}\text { Limpeza } \\
\text { Conservação } \\
\text { Organização } \\
\text { Vedação } \\
\text { Infraestruturas de apoio } \\
\text { Vestígios arqueológicos }\end{array}$ \\
\hline Divulgação & \\
\hline $\begin{array}{l}\text { Recursos } \\
\text { Didáticos }\end{array}$ & $\begin{array}{l}\text { Apresentação multimedia } \\
\text { Informação fornecida pelo } \\
\text { Santuário de Panóias }\end{array}$ \\
\hline $\begin{array}{l}\text { Melhorias } \\
\text { sentidas }\end{array}$ & \\
\hline $\begin{array}{l}\text { Interesse para a } \\
\text { cultura e } \\
\text { Sociedade } \\
\text { Portuguesa }\end{array}$ & \\
\hline
\end{tabular}

Fonte: Teixeira (2013:67)

Para investigar um leque de aspetos relevantes acerca do Santuário de Panóias, tais como o seu funcionamento, barreiras arquitetónicas que prejudicam a circulação durante a visita, contributo para a cultura e sociedade portuguesa, foi aplicada a entrevista por permitir a obtenção de respostas diretas e informações mais completas.

"A entrevista é um método de recolha de informações que consiste em conversas orais, individuais ou de grupos, com várias pessoas selecionadas cuidadosamente, a fim de obter informações sobre factos ou representações, cujo grau de pertinência, validade e fiabilidade é analisado na perspetiva dos objetivos da recolha de informações" (DE KETELE \& ROGIERS, 1999,p.150).

Como um dos objetivos deste estudo foi também compreender o funcionamento do Santuário de Panóias nas suas diferentes dimensões, bem como considerar estratégias a programar como forma de promover o seu crescimento e o desenvolvimento deste, enquanto Património Nacional, resolvemos entrevistar o responsável pela gestão do Monumento, bem como o único funcionário existente - guia do Santuário.

A grelha de observação direta "constituem os únicos métodos de investigação que captam os comportamentos no momento em que eles se produzem, sem a mediação de um documento ou de um testemunho" (QUIVY\& CAMPENHOUDT,2003,p.72). Desta forma, o investigador pode estar atento ao aparecimento ou à transformação dos comportamentos, aos efeitos que eles produzem e aos contextos em que são observados.

Pretendeu-se com verificar quais os itens que se destacaram no contexto de uma visita ao Santuário de Panóias. Neste instrumento foi introduzido uma escala que variou entre "Insuficiente" e "Muito bom", com o objetivo de o investigador avaliar de forma precisa todas as dimensões propostas.

\section{- Tratamento e análise de dados}

Para o tratamento dos dados, utilizaram-se como métodos de análise a estatística descritiva e a análise de conteúdo. Desta forma, os dados recolhidos através dos inquéritos por questionário $(A$ B) foram tratados através da estatística descritiva, enquanto os dados recolhidos através dos inquéritos por entrevista, e grelha de observação, foram tratados através da análise de conteúdo.

\section{Resultados e análise empírica}

- Caracterização sociodemográfica da amostra 
A amostra para esta investigação foi recolhida entre 1996 e 1999 e entre 2006 e 2011 e contou com 711 inquiridos, aos quais foi aplicado o inquérito por questionário, após o término da visita guiada ao Santuário.

Gráfico 01: Classificação por sexo dos inquiridos

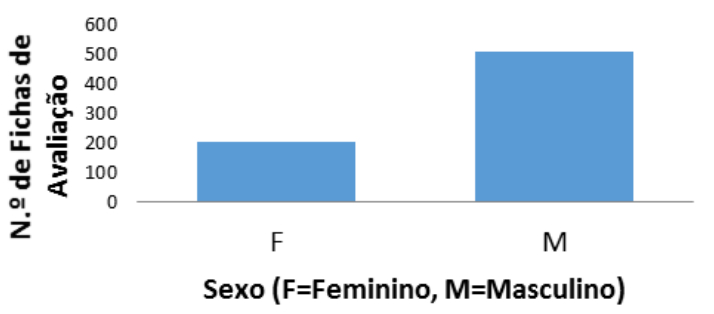

Fonte: TEIXEIRA (2013,p.72)

Num universo de 711 questionários analisados entre 1996 a 1999 e 2006 a 2011, confere-se que $28,7 \% \quad(n=204)$ dos visitantes pertencem ao sexo feminino e $71, \%(n=507)$ ao sexo masculino. Desde já notamos uma grande discrepância que foi melhor entendida nas entrevistas realizadas. Ou seja, não houve preocupação dos responsáveis pelo Monumento em solicitar a participação de todos os visitantes, assim quando viajavam em grupo, geralmente quem preenchia 0 inquérito era 0 elemento masculino. Embora não se retirem dados concretos sobre o sexo dos visitantes, a análise deste gráfico e o entendimento da diferença entre o género dos visitantes permitiu que no futuro a preocupação aumentasse quanto ao preenchimento dos questionários.
Gráfico 02: Distribuição geográfica dos visitantes estrangeiro

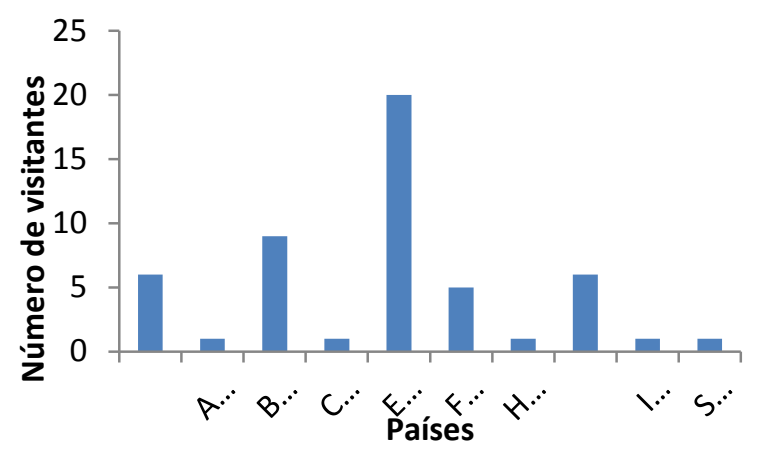

FONTE: TEIXEIRA (2013,p.73)

No que concerne à nacionalidade dos inquiridos, constata-se um predomínio de visitantes portugueses, $83,2 \% \quad(n=592)$ em contraponto com $16,8 \% \quad(n=119)$ de visitantes de nacionalidade estrangeira. Dos 119 inquiridos de nacionalidade estrangeira, apenas 45 divulgaram o seu país de origem, dos quais destacamos 20 espanhóis, 9 brasileiros, 6 alemães, 6 ingleses, 1 austríaco, 1 canadense, 1 italiano e 1 suíço. Note-se que a visita de estrangeiros é muito parca pelo que nos aponta para uma diminuta informação nas redes turísticas locais, regionais ou nacionais.

Gráfico 03: Distribuição geográfica dos visitantes portugueses

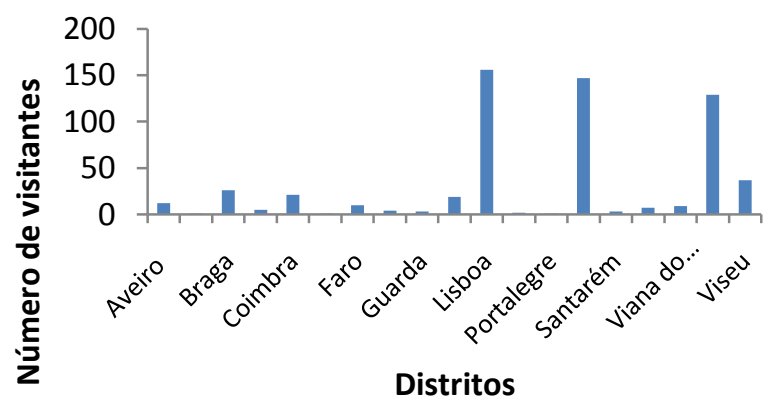

FONTE: TEIXEIRA (2013,p.74)

Dos 592 visitantes portugueses constata-se que $26,4 \% \quad(n=156)$ provém do distrito de Lisboa, $24,8 \%(n=147)$ do distrito do Porto, $21,8 \%(n=129)$ do distrito de Vila Real, 6,3\% $(n=37)$ do distrito de Viseu, 
4,4\% ( $n=269$ do distrito de Braga, 3,5\% ( $n=21)$ do distrito de Coimbra, 3,2\% $(n=19)$ do distrito de Leiria, $2,0 \%(n=12)$ do distrito de Aveiro, 1,7\% $(n=10)$ do distrito de Faro, 1,5\% $(n=9)$ do distrito de Viana do Castelo, 1,2\% ( $n=7)$ do distrito de Setúbal, 0,8\% ( $n=5)$ do distrito de Castelo Branco, 0,5\% $(n=3)$ do distrito de Santarém, 0,5\% $(n=3)$ do distrito da Guarda, 0,7\% $(n=4)$ do distrito do Funchal, $0,3 \%(n=2)$ do distrito de Ponta Delgada, 0,2\% $(n=1)$ do distrito de Portalegre, $0,2 \%(n=1)$ do distrito de Évora.

Observa-se, assim, uma predominância de visitantes das grandes áreas urbanas, Porto e Lisboa, e do próprio distrito onde o monumento se localiza. Os públicos das restantes áreas nacionais é muito restrito. Aqui podemos destacar a questão da falta de informação e da sua distribuição pelo território nacional ou, por outro lado, a falta de interesse dos públicos fora das grandes áreas urbanas.

\section{Gráfico 04: Profissão dos inquiridos}

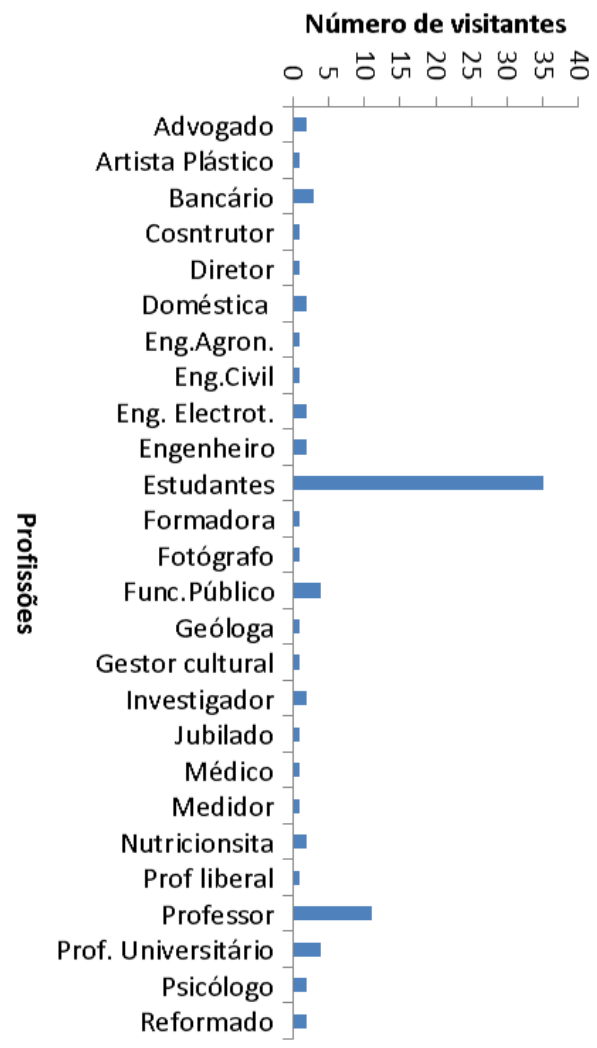

FONTE: Teixeira (2013,p.75)
Dos 711 visitantes que contemplaram o universo da amostra, 88\% ( $n=624)$ não mencionaram a sua profissão. Note-se que a enorme lacuna que acompanha esta situação e permite, mais uma vez, concentrar a atenção no preenchimento dos questionários e na sensibilização do público para os mesmos. Dos $12 \%$ que responderam $(n=87)$, pode-se constatar que existe uma vasta variedade em termos de estrutura profissional dos visitantes. De acordo com o Gráfico $n^{\circ} 4,40 \%(n=35)$ dos inquiridos são estudantes, 17\% ( $n=11)$ são professores, 9\% $(n=6)$ são engenheiros, $5 \% \quad(n=4$ são professores universitários), $5 \%(n=4)$ são funcionários públicos), 3,4\% ( $n=3)$ são bancários, 2,2\% ( $n=2)$ são psicólogos, $2,2 \% \quad(n=2)$ são reformados, 2,2\% $(n=2)$ são nutricionistas, 2,2\% ( $n=2)$ são investigadores, 2,2\% $(\mathrm{n}=2)$ são domésticos, 2,2\% $(\mathrm{n}=2)$ administradores, 1 é profissional liberal, 1 é medidor orçamentista, 1,1\% $(\mathrm{n}=1)$ é médico, $1,1 \%(\mathrm{n}=1)$ é jubilado, $1,1 \%(\mathrm{n}=1)$ é geólogo, 1,1\% $(n=1)$ é gestor cultural, $1,1 \%(n=1)$ é fotógrafo, $1,1 \%(n=1)$ é formador, $1,1 \%(n=1)$ diretor, $1,1 \%(n=1)$ consultor, $1,1 \%(n=1)$ artista plástico e 1,1 $(n=1)$ advogado

\section{Gráfico 05: Número de visitantes por ano civil}

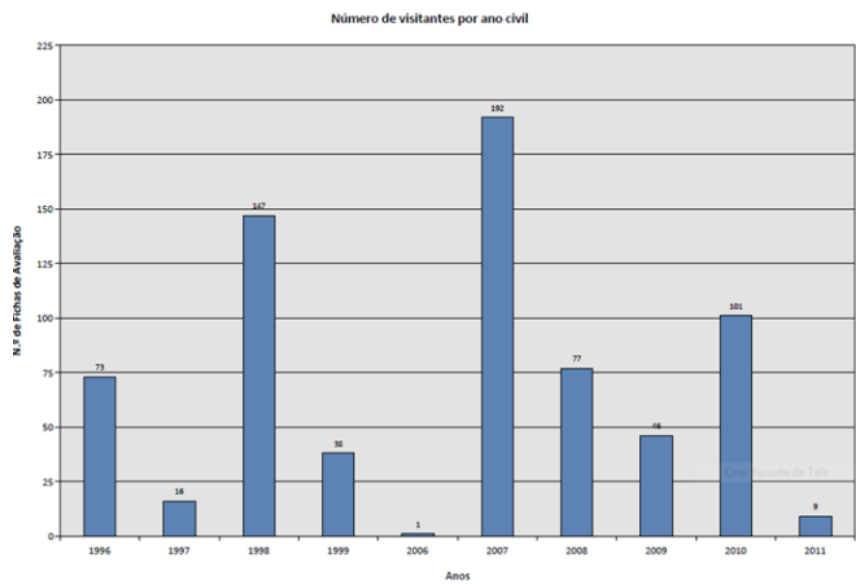

FONTE: TEIXEIRA(2013,p.76)

Analisar o número de visitantes ao Santuário de Panóias tornou-se preponderante para a nossa investigação, pelo facto de se terem registado variações consideráveis no número de visitas ao longo dos anos. O período de análise contemplado ocorreu entre os anos de 1996 e 1999 e entre 2006 e 
2011. Este interregno na aplicação dos questionários deveu-se ao facto de terem ocorrido no Monumento algumas mudanças em termos logísticos, que contribuíram para uma total ausência de respostas neste período, e para uma variação considerável da aplicação do mesmo, ao longo dos restantes anos.

No entanto é de ressalvar, que em certos casos, visitantes recusaram o preenchimento do Inquérito, e em grupos numerosos, regra geral, apenas uma pessoa é que preenchia o documento.Constatou-se que no ano de 1996 visitaram o Santuário de Panóias 73 visitantes, em contrapondo com o ano de 1997, em que apenas 16 visitantes estiverem presentes no monumento.Em 1998, o número de visitantes aumentou significativamente para 147; já em 1999 verificou-se uma quebra para 38 visitantes.Em 2006, o Santuário de Panóias contou apenas com a presença de 1 visitante; este número disparou em 2007 para 192 visitantes. Voltou a sentir-se uma quebra nos anos de 2008 e 2009, onde o monumento contou apenas com 77 e 46 visitantes prospectivamente.Em 2010 estes valores voltaram a subir para 101 visitantes e, em 2011 apenas de verificou a presença de 9 visitantes

- Avaliação global do Santuário de Panóias pelos inquiridos

Um dos principais objetivos deste trabalho foi questionar os visitantes a respeito da sua satisfação global no que concerne à visita ao Monumento. Esta análise, conforme anteriormente referido, foi baseada nos parâmetros incluídos nos dois inquéritos desenvolvidos pela Direção Regional da Cultura do Norte: acessibilidades, condições materiais do espaço, atendimento ao público, materiais de apoio, interpretação do sítio, aspetos positivos e aspetos negativos do Monumento.De forma geral, podemos concluir que a opinião dos inquiridos é unânime, demonstrando um elevado nível de satisfação, o que demonstra que a visita cultural é do agrado de quem a visita, promovendo-se uma maior visibilidade deste espaço e termos culturais.
Gráfico n6: Análise comparativa da apreciação global da visita por sexo

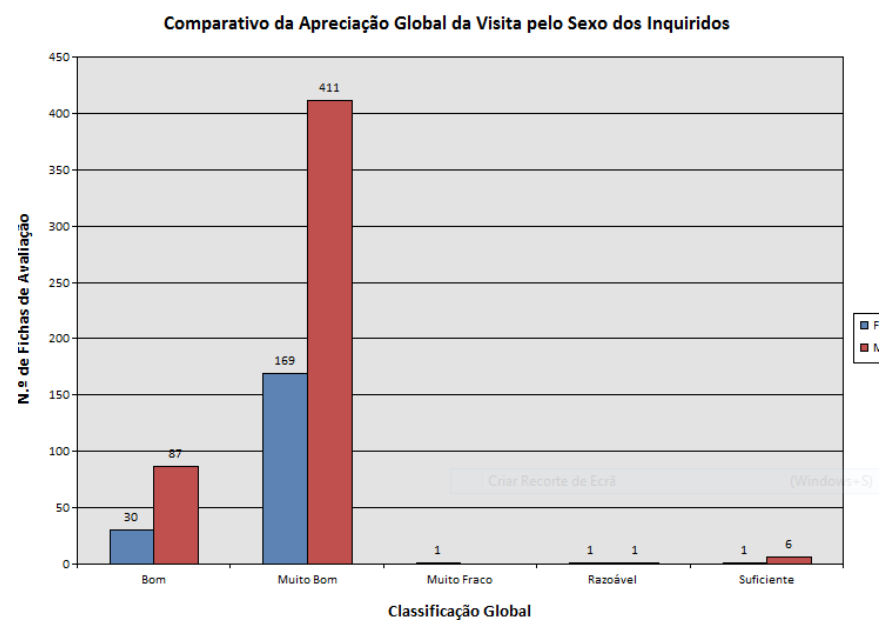

FONTE: TEIXEIRA (2013,p.9)

Concluímos que é coincidente a opinião dos $79 \%(n=411)$ dos inquiridos do sexo masculino e $83 \%$ $(n=169)$ do sexo feminino, avaliaram o Santuário de Panóias como sendo muito bom. Por outro lado, $17,1 \%(n=87)$ dos inquiridos do sexo masculino e $15 \% \quad(n=30)$ do sexo feminino, consideraram o Monumento como sendo bom. Por fim, 1,1\% $(n=6)$ inquiridos do sexo masculino e $0,4 \%(n=1)$ do sexo feminino julgaram o Santuário como sendo suficiente; $0,2 \%(n=1)$ inquiridos do sexo masculino e $0,4 \%$ do sexo feminino $(n=1)$ avaliaram o Monumento como razoável e apenas $0,2 \%(n=1)$ inquiridos do sexo masculino avaliaram o Santuário de Panóias como sendo muito fraco. Proporcionalmente parece que homens e mulheres mantêm o mesmo nível de avaliação e de exigência perante a visitante, não transparecendo maior a exigência nuns que noutros, no entanto, a conclusão não é de forma alguma fiável dada a diferença de amostragem. 
Gráfico n7: Análise comparativa da apreciação global por área de residência dos inquiridos

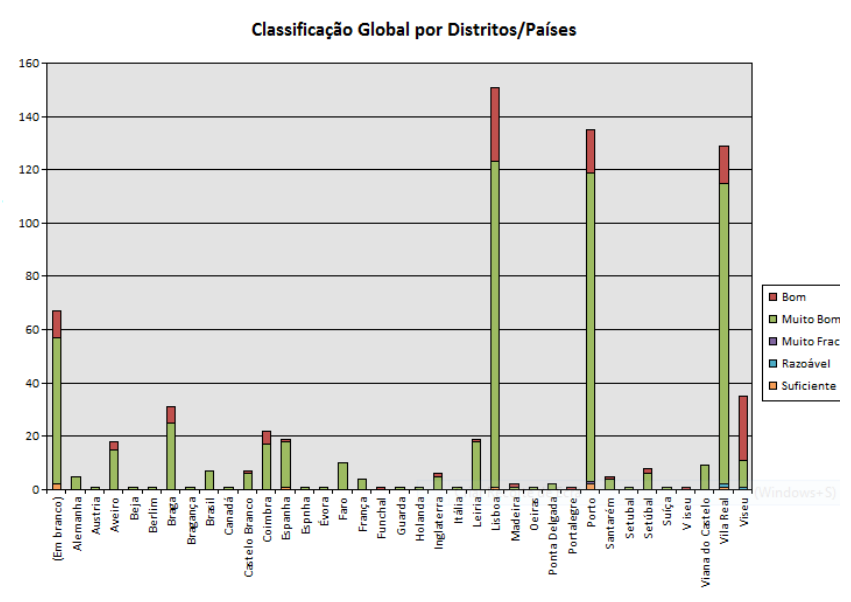

Distritos/Paises

FONTE: TEIXEIRA (2013,p.10)

A partir da análise do gráfico, foi possível concluir que os 711 inquiridos que constituíram a amostra avaliaram o Monumento em termos de classificação global. Sendo assim, 8,4\% ( $n=60)$ visitantes consideraram-no como muito bom, $1 \%$ $(n=7)$ como bom e apenas $0,2 \% \quad(n=2)$ como suficiente.Analisando os visitantes de origem portuguesa destacam-se primeiramente aqueles que avaliaram unanimemente o Santuário como sendo muito bom e bom. Estes provêm de Beja, Bragança, Évora, Oeiras, Ponta Delgada, Setúbal, Guarda, Viana do Castelo, Aveiro, Braga, Castelo Branco, Coimbra, Santarém, Vila Real, Viseu e Faro. Analogamente, os visitantes estrangeiros, na sua generalidade avaliaram o Monumento na sua maioria como sendo muito bom, o que denota uma satisfação do público estrangeiro com este espaço cultural.
Gráfico n8: Análise comparativa da apreciação global por profissões dos inquiridos

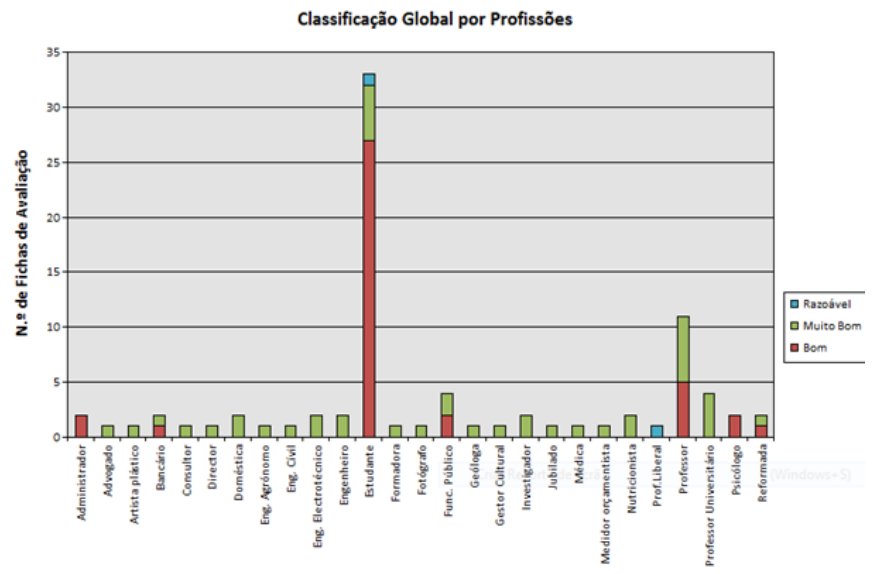

FONTE: TEIXEIRA(2013,p.11)

Destacamos que todos consideraram 0 Monumento de muito bom ou bom. Apenas uma pessoa registou como razoável. Pretendemos destacar a opinião do público escolar e verificar se esta tendia em sentido inverso à generalidade das classificações. Verificou-se que se mantém inalterável a classificação de muito bom e bom, registando apenas uma opinião de razoável.

Gráfico n9: Análise comparativa da Classificação Global por ano civil

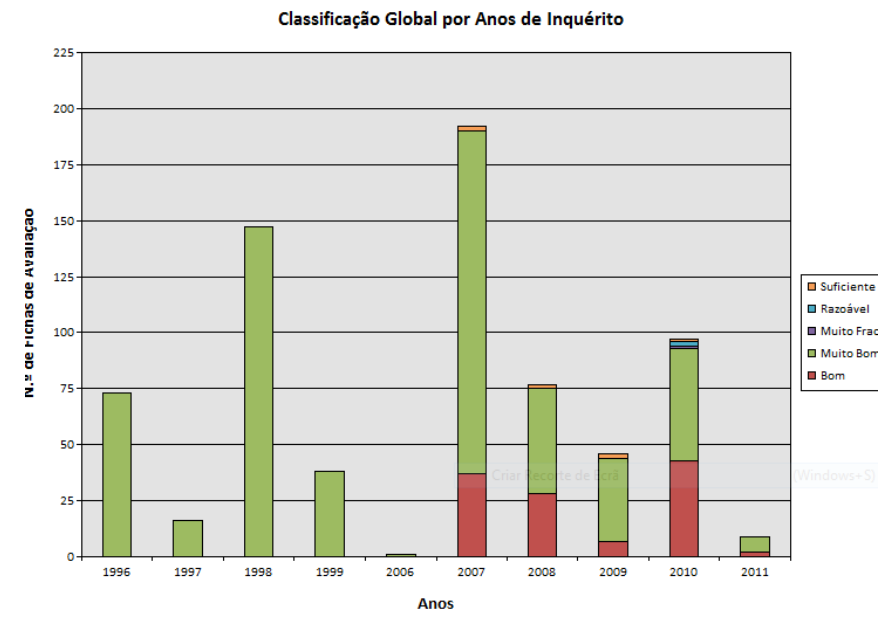

FONTE: TEIXEIRA (2013,p.11)

Mediante a análise do gráfico, concluímos que nos anos de 1996, 1997, 1998, 1999 e 2006 o Santuário de Panóias foi avaliado unanimemente por todos os visitantes como sendo muito bom, em 
termos de classificação global. No ano de 2007, 79\% $(n=153)$ dos visitantes avaliaram o Monumento como muito bom; 19,2\% ( $n=37)$ como bom e apenas 1\% $(\mathrm{n}=2)$ dos visitantes como suficiente. O mesmo fenómeno ocorreu em 2008.

\section{- Narrações dos inquiridos}

A partir dos dados recolhidos pela análise dos inquéritos por questionário, foi possível categorizar um conjunto de dimensões, que estiveram na base da análise de conteúdo e da conclusão dos resultados finais deste trabalho. Neste caso em concreto, a análise de conteúdo "oferece a possibilidade de tratar de forma metódica informações e testemunhos que apresentam um grau de profundidade e de complexidade e permite, quando incide sobre um material rico e pertinente, satisfazer as exigências do rigor metodológico e da profundidade inventiva, que nem sempre são facilmente conciliáveis" (QUIVY\& CAMPENHOUDT, 2003,p.80).

Assim sendo, iremos citar algumas das opiniões dos nossos inquiridos acerca das várias dimensões que foram categorizadas através do método da análise de conteúdo.

Foi-nos possível concluir que a receção ao visitante foi considerada, pela maioria dos inquiridos, como sendo "muito calorosa e agradável", com "excelentes condições de tratamento aos mesmos" e "funcionários exemplares, muito conhecedores" "sempre disponíveis". O acolhimento foi ainda avaliado como sendo "excelente", "exemplar", com uma "receção de alta qualidade" e com "ótimo apoio por parte dos funcionários" do Santuário de Panóias.

A visita guiada foi avaliada como "excelente", muito bem "dirigida, organizada e orientada", bem como "motivadora", "elucidativa" e "esclarecedora" na medida em que "proporcionou novos conhecimentos", pela generalidade dos visitantes que constituíram a amostra. Destacaram o "excelente trabalho do guia, Sr. Herculano", na medida em que proporcionou aos visitantes "um acompanhamento muito personalizado" e "explicações muito esclarecedoras" acerca do Santuário de Panóias.
Os acessos foram considerados por alguns visitantes como apresentando "boas condições" e com "fácil acesso às ruinas". No entanto uma grande maioria considerou que estes deveriam "ser melhorados", bem como deveriam existir "transportes diretos para o local".

A sinalização até ao Santuário de Panóias foi avaliada como "péssima e sem informação visível" pela grande maioria dos visitantes.

Relativamente à conservação do Monumento, conclui-se que este foi considerado pela maioria dos visitantes como sendo "um local muito bem cuidado e preservado", com "excelentes condições de tratamento do recinto envolvente".

De uma forma geral, as infraestruturas de apoio foram entendidas pela grande generalidade dos inquiridos como sendo "apropriadas" e estando em "boas condições". Algumas das mesmas poderiam ser "melhoradas" de forma a garantir um "melhor funcionamento e segurança do Santuário", relatam os visitantes.

A grande maioria dos inquiridos considerou que "deveria existir uma maior divulgação do Santuário de Panóias a nível nacional e internacional".

O apoio multimédia foi avaliado como sendo "excelente" e "muito interessante", destacando-se o filme de apresentação inicial do Santuário de Panóias avaliado como "muito interessante", "conciso", "elucidativo" e "excelente".

Finalizando, os visitantes consideraram o Monumento "um local apaixonante e de grande importância para a cultura portuguesa", referindo que "ficaram mais enriquecidos culturalmente" e "aprofundaram os seus conhecimentos sociais, culturais e religiosos".

\section{Considerações finais}

Indo ao encontro de um dos objetivos desta investigação, ficou atente que os visitantes do Santuário de Panóias, entre os anos estudados, foram aqueles que que têm menor representatividade na população portuguesa: um público escolarizado e 
qualificado.Desta feita, caraterizaram-se por serem maioritariamente do sexo feminino, porpossuírem habilitações académicas elevadas, profissões qualificadas e por serem detentores de um forte capital cultural já intrínseco e enraizado.Este desfecho vem também, ao encontro do que SANTOS (2003,p.77) salienta nos seus estudos: "os consumos culturais permanecem estreitamente correlacionados com o nível de instrução, e, por essa via, com a condição socioprofissional" (SANTOS,2003,p.77).

A incrementação de uma maior proximidade entre os públicos menos habilitados e a "cultura da arte" requererá segundo SANTOS (2003,p.78) "um aperfeiçoamento dos processos de familiarização precoce e prolongada com os campos culturais mais seletivos", ou seja, o resultado desta investigação vêm confirmar a importância destes Monumentos no processo de enriquecimento cultural dos seus visitantes, uma vez que faculta a possibilidade de adquirirem competências imprescindíveis em contextos diferenciados. É neste sentido, que reconhecemos o Santuário de Panóias como um espaço pedagógico por excelência, que reafirma a identidade local, recupera tradições atualmente em declínio, promove a cultura local e reforça a autoestima das populações residentes, constituindo um foco dinamizador de cultura e de desenvolvimento.

\section{Referências}

AlBARELlO, L. et al. Práticas e Métodos de Investigação em Ciências Sociais - Trajectos. Lisboa: Gradiva,p.84-116,1997.

ALFOLDY, G. Die Mysterien von Panóias (Vila Real Portugal), Madrider Mitteilungen, $\mathrm{n}$ ㅇ 38, 1997, 176$246,1997$.

ARGOTE, J. Memórias para a História Ecclesiástica do Arcebispado de Braga,1734.

BARATA, F. Preservando a memória do território: O parque natural de Tourega/Valverde. Évora: Edição do Centro de Ecossistemas Mediterrânicos, Universidade de Évora,1-164,2002.

CARVALHO, J. Filosofia da cultura: Delfim Santos e o pensamento contemporâneo. Porto Alegre: Edipucrs,p.1-150,1999.
CASSOLA,L. Turismo y ambiente. México: Ed. Trillas, 1990.

DE KETELE, J.; ROGIERS. Metodologia da Recolha de Dados. Fundamentos dos Métodos de Observações, de Questionários, de Entrevistas e de Estudo de documentos. Lisboa: Instituto Piaget, 1999.

FRAGOSO, A. Avaliação de Projetos Sociais: O Caso do Projeto "Entre-mães". Revista de Educação, v. IX, n.2, p. $15-25,2000$

ICOMOS. Carta de Veneza: Carta Internacional sobre a Conservação e o Restauro de Monumentos e Sítios,1964. In Textos Fundamentais, no 1 , Évora,1996.

ICOMOS (2008). Carta dos itinerários culturais. Canadá.

IGESPAR, IP. (2009). Carta de Bruxelas sobre o papel do património cultural na economia, e para a criação de uma rede europeia de seu reconhecimento e divulgação.

JORGE, V. Património e Identidade Nacional. Engenharia Civil, nำ, 1-8,2000.

KLAMER, A. A Reevaluation of Values. In Economics. Quarterly Journal of Budapest University of Economics Sciencies, Vol. XXI, No.4, p.30-45,2000.

PORTUGAL. Lei do Património Cultural: Lei $\mathrm{n} . \stackrel{0}{0}$ 107/2001 de 8 de Setembro.

QUIVY, R. \& CAMPENHOUDT, L. Manual de Investigação em Ciências Sociais. Lisboa: Gradiva,2003.

RUÍZ, C. Historia y evolucion del pensamiento cientifico. Mexico,p.1-162,2006. Disponível:www.monografias.com/trabajos.pdf/historia -pensamiento.cientifico/historiapensamiento.cientifico.shtml

SANTOS, H. A propósito dos públicos culturais: uma reflexão ilustrada para um caso português. In Revista Crítica de Ciências Sociais, ํㅜ․67, 75-97,2003.

TEIXEIRA, R. Cultura e a Diversidade de Públicos um estudo de caso. Tese de Mestrado em Ciências da Educação, especialização em Educação Social. Porto: Universidade Portucalense Infante D. Henrique,2013.

TUCKMAN, W. Manual de Investigação em Educação. Lisboa: Fundação Calouste Gulbenkian,1742,2000

UNESCO. Convenção para a protecção do Património mundial, cultural e natural. Paris.

UNESCO Cultural Heritage Laws Database as the source,1972. 
UNESCO. Carta de Cracóvia 2000: Principios para la conservación y retauración del patrimonio construído. Compendio del leyes sobre la proteción del patrimonio cultural de Guatemala. Guatemala:

UNESCO Cultural Heritage Laws Database as the source, 2000.

UNESCO. Convenção de Faro: Quadro com Conselho da Europa relativa ao valor do Património Cultural para a sociedade. Faro: UNESCO Cultural Heritage Laws Database as the source,2005.

VINUESA, M. Patrimonio Cultural: Valorización económica y reutilización funcional. Madrid: Universidad Complutense de Madrid,p. 1-2ํㅡㄹ.

YIN, R. Estudo de Caso. Planejamento e Métodos. Porto Alegre: Bookman,2005. 